\title{
Blocking in eyelid conditioning: Effect of changing the CS-US interval and introducing an intertrial stimulus
}

\author{
ROBERT T. MALESKE and PETER W. FREY \\ Northwestern University, Evanston, Illinois 60201
}

\begin{abstract}
Kamin's three-stage blocking paradigm was investigated in rabbit eyelid conditioning. Two manipulations were examined. A change in the CS-US interval from Stage 1 to Stage 2 did not attenuate blocking. The introduction of a salient stimulus during the intertrial interval in Stage 2 also failed to attenuate blocking. The first result is not consistent with Kamin's interpretation of the blocking effect in terms of US surprisingness. The second result is in consistent with a prediction based on the Rescorla-Wagner model.
\end{abstract}

Kamin (1969) examined a procedure which is presently referred to as the blocking paradigm. The experimental group receives conditioning trials with one stimulus (A) for several sessions until it regularly elicits a conditioned response. In the second phase of the experiment, this stimulus (A) is combined with another stimulus (B) and the compound is then reinforced for several sessions. The third phase consists of test trials in which the associative strength of the added stimulus (B) is measured. The standard control group receives no conditioning during Phase 1 , reinforced $A B$ trials during Phase 2, and test trials with B during Phase 3. Kamin observed that the training experience with stimulus A "blocked" learning to stimulus $B$ when the $A B$ compound was reinforced in Phase 2 . This effect has been replicated many times in the CER paradigm and has also been demonstrated in rabbit eyeblink conditioning (Marchant \& Moore, 1973), in instrumental appetitive conditioning in fish (Tennant \& Bitterman, 1975), in an operant paradigm with pigeons (e.g., Williams, 1975), and with conditioned inhibition in the CER paradigm (Suiter \& LoLordo, 1971).

Kamin's (1969) study indicated that the rats noticed the introduction of stimulus B during Phase 2 and therefore he concluded that the blocking phenomenon was not produced by a selective attention process. Instead, Kamin (1969, p. 293) suggested that: "for an increment in associative connection to occur, it is necessary that the US provoke the animal

This research was supported by National Science Foundation Grants BMS75-02313 and BNS77-00158 and is based on a doctoral dissertation submitted by the first author to the Graduate School of Northwestern University in partial fulfillment of the requirements for the PhD degree. Reprints may be obtained from Peter Frey, Department of Psychology, Northwestern University, Evanston, Illinois 60201. Robert Maleske's present address is Department of Psychology, Carthage College, Kenosha, Wisconsin 53140 . into a backward scanning of its memory store of recent stimulus input; only as a result of such a scan can an association between CS and US be formed, and the scan is prompted only by an unpredicted US, the occurrence of which is surprising." In this view, the reinforced A trials during Phase 1 make $A$ a reliable predictor of the occurrence of the US and thereby make the US ineffective for producing new learning during the $A B$ trials which follow. This idea has been formalized (Rescorla \& Wagner, 1972) by assuming that increases in associative strength on any given trial are directly proportional to the quantity $\lambda-\bar{V}$ where $\lambda$ is the asymptotic level of associative strength that a given US will support and $\bar{V}$ is the aggregate associative strength of all cues present on that trial.

This theoretical representation is consistent with demonstrations that blocking can be attenuated by increasing the intensity of the shock US at the beginning of Phase 2 (Kamin, 1969). The model represents this change as an increase in the asymptotic level of the associative process, $\lambda$, and thereby predicts learning in Phase 2 because $\bar{V}$ is now less than $\lambda$. Research which shows that blocking can be attenuated by a very brief second presentation of the CS beginning $3 \mathrm{sec}$ after the conventional $\mathrm{AB}$ trial in Phase 2 (Gray \& Appignanesi, 1973) or by the omission of an expected duplicate shock in Phase 2 (Dickinson, Hall, \& Mackintosh, 1976) is also consistent with this model. Neely \& Wagner (1974) have noted that any event which markedly changes the background context at the beginning of Phase 2 should reduce the value of $\bar{V}$ (by generalization decrement) and thereby permit additional learning since $\bar{V}$ is less than $\lambda$.

The present study examines two manipulations which are related to this interpretation of the blocking phenomena. Rescorla (1971) has demonstrated that blocking can be observed in fear conditioning 
when the time interval between CS onset and US onset is variable. In this case, the stimulus employed during the initial training predicts the US but not its exact time of occurrence. This finding is interesting because one might expect, given Kamin's hypothesis, that any uncertainty about when the US will occur would attenuate blocking. Kohler and Ayres (1979) have recently examined this paradigm in more detail and found similar results. Variation in the CS-US interval during fear conditioning in the first phase of the blocking paradigm did not attenuate blocking when the new stimulus was introduced in Phase 2 under either a fixed or a variable CS-US interval.

The present study examined this manipulation in a different response system. There is considerable evidence that eyeblink conditioning is dependent on the maintenance of a fixed CS-US interval (e.g., Boneau, 1958; Coleman \& Gormezano, 1971; Frey, 1970; Leonard \& Theois, 1967; Prokasy \& Papsdorf, 1965). Empirical results indicate that the associative connection between the CS and US in eyeblink conditioning is specific to a particular timing relationship between the CS and US. In this context, a variable CS-US interval should be more likely to attenuate blocking.

An additional manipulation which was examined in the present study was the presentation of a novel salient stimulus during the second phase of the blocking paradigm. Neely and Wagner (1974) have argued that a contextual change during Phase 2 will decrease $\bar{V}$ and thus increase $\lambda-\bar{V}$. This should attenuate blocking. Our manipulation is similar to that employed in earlier eyeblink conditioning research (Grevert \& Moore, 1970; Kettlewell \& Papsdorf, 1967; Papsdorf \& Kettlewell, 1968) in that a salient stimulus is presented during the intertrial interval. The primary difference with these earlier studies is that the interpolated stimulus in the present study was introduced after the animals had reliably acquired a CR rather than during the acquisition process. Although the interpolated stimulus in the present study was a vibrotactile stimulus rather than an electric shock, prior research has demonstrated that this stimulus is highly salient (Frey \& Gavin, 1975, Experiment 2).

\section{METHOD}

\section{Subjects}

The subjects were 84 male rabbits of the American Dutch strain (black or brown with white patches) and were 12 to 15 weeks of age upon arrival. Fourteen animals were eliminated during the course of the study due to sickness, equipment failure, or experimenter error. The animals had free access to Purina Rabbit Chow and water in the colony room and were housed individually. Housing conditions included temperature control $\left(21^{\circ} \pm 2^{\circ} \mathrm{C}\right)$ and humidity control $(35 \%$ to $65 \%$ relative $)$ and illumination from overhead fluorescent lights from $6 \mathrm{a} . \mathrm{m}$. to 10 p.m. each day.

\section{Apparatus}

The subjects were restrained during each conditioning session in a Plexiglas stock $(12 \times 14 \times 50 \mathrm{~cm})$ which permitted movement of the limbs within the stock and partial rotation of the head, which protruded through an opening above the stock (see Frey \& Gavin, 1975, Figure 1). Six rabbits were conditioned at a time in a sound-attenuated, walk-in chamber $(2.3 \times 2.0 \times$ $2.6 \mathrm{~m}$ ), which was illuminated by a $7.5-\mathrm{W}$ incandescent red light attached to the ceiling. The chamber was ventilated, and the temperature $\left(20^{\circ} \pm 1^{\circ} \mathrm{C}\right)$ and humidity $(50 \% \pm 10 \%)$ were controlled. A background sound level was maintained at $72 \mathrm{~dB}$ (SPL) by presenting white noise (Grason-Stadler noise generator, model $901 \mathrm{~B}$ ) through four speakers located in the upper four corners of the chamber.

Eyelid movements were graphically recorded with a counter weighted minitorque potentiometer (Conrac Corp., Model 85153), an amplification system similar to that described by Goodrich, Markowitz, and Norman (1964), and a Beckman Model 504D vertical drive oscillograph. The US was a 3-msec cheek shock produced by the discharge of a $.1-\mu \mathrm{F}$ capacitor which was charged to a level of $200 \mathrm{~V} \mathrm{dc}$.

Three different stimuli were used as CSs: an overhead strobe light (A), a $1,000-\mathrm{Hz}$ tone $(\mathrm{B})$, and a $60-\mathrm{Hz}$ vibration of the stock floor (X). The strobe light (EDI Corp., Model CF-16) was attached to the ceiling of the chamber and was set for a flash rate of $7 / \mathrm{sec}$. The tone CS of $1,000 \mathrm{~Hz}$ (Hewlett Packard audio oscillator, Model 200 ABR) was presented through six separate speakers located in front of each subject. In combination with the white noise, the tone produced a sound level of $82 \mathrm{~dB}$ (General Radio sound-level meter, Type 1565-A, Scale Bs). The vibrotactile CS was produced by a solenoid attached underneath the Plexiglas floor of each stock. The solenoid acted upon a strong spring anchored to the floor of the stock.

\section{Procedure}

After delivery by a local supplier, the subjects were habituated to their new cages for at least 2 days prior to surgery. The subsequent surgical procedure was preceded by a .3-cc IP injection of atropine and was performed while the animal was anesthetized with sodium pentobarbital. Two lengths of 26-ga suturing wire were attached below and to etiher side of the right eye, and later served as shock electrodes. Two stainless steel bolts $(2-56,13 \mathrm{~mm})$ were embedded into the top of the skull and secured with dental cement. A rectangular tab of Velcro fastener (American Thread Co.) was attached using Davol surgical adhesive to the right eyelid. On the 2nd day following surgery, each animal was introduced to the stock and conditioning chamber in the following manner: $15 \mathrm{~min}$ in the stock unrestrained, $15 \mathrm{~min}$ in the stock restrained, $30 \mathrm{~min}$ in the stock restrained with all recording and stimulating equipment attached. The recording potentiometer was attached to a small Plexiglas platform mounted on the rabbit's head by means of the implanted bolts. The arm of the potentiometer was connected to the Velcro eyelid pad with a length of suturing thread, and flexible wire was connected to the cheek electrodes using miniature collet-type jewelry clasps.

\section{Design}

All groups received three separate phases of training. These phases correspond to the basic "blocking" procedure described by Kamin (1969). There were five sessions (days of training in Phase 1, 3 days in Phase 2, and 2 days in Phase 3. Each session consisted of 60 conditioning trials at an average intertrial interval of $90 \mathrm{sec}(75$ to $105 \mathrm{sec})$. The CS always overlapped the US and was either 600 or $1,100 \mathrm{msec}$ in duration, depending on whether the CS-US interval was 500 or 1,000 msec.

During Phase 1, two groups received habituation sessions only $(\mathrm{HAB}, \mathrm{HAB}-\mathrm{X})$, two received acquisition to the strobe light at a 500-msec CS-US interval (A-500, A-500-X), two received acquisition to the strobe light at a $1,000 \mathrm{msec}$ CS-US interval (A-1000, 
A-1000-X), and one group received acquisition training to the vibrotactile stimulus at a 500-msec CS-US interval (X-500). Twelve animals were assigned to each of these conditions at the beginning of training.

During Phase 2, four of the groups (HAB, A-1000, A-500, and $X-500$ ) received conditioning trials in which a compound composed of the strobe light and the tone was paired with the US at a 1,000-msec CS-US interval. The three other groups (HAB-X, A-1000-X, and A-500-X) received this same treatment and, in addition, experienced the vibrotactile CS midway (i.e., $45 \mathrm{sec}$ ) through the intertrial interval. This additional stimulus was not followed by the US. In Phase 3, the tone was paired with the US at a 1,000 -msec CS-US interval for all groups. These treatments are summarized in Table 1.

\section{RESULTS AND DISCUSSION}

A CR was defined as a $2-\mathrm{mm}$ or greater pen deflection in a direction indicating closure during a time interval which started $120 \mathrm{msec}$ after CS onset and ended $20 \mathrm{msec}$ after US onset. The gain of the recording system was adjusted so that a full eyelid closure produced a pen deflection of 20 to $25 \mathrm{~mm}$.

The performance on the last day of Phase 1 and Phase 2 and on the 1 st day of Phase 3 is summarized in Table 1. All groups, with the exception of HAB and $\mathrm{HAB}-\mathrm{X}$, reached a high level of responding by the end of Phase 1. By the end of Phase 2, all groups were also responding at a high level to the $\mathrm{AB}$ compound.

In order to examine the effectiveness of the experimental manipulations, an analysis of the performance of specific groups was made at the beginning of Phase 2 . The two groups receiving habituation training in Phase 1 (HAB and HAB-X) showed a response level of $2.0 \%$ on the first 10 trials of Phase 2 . This result indicates that the tone-light compound did not evoke CRs in the absence of prior CS-US pairings. The group which had the vibrotactile stimulus paired with the US during Phase 1 (X-500) responded $12.2 \%$ of the time on the first 10 trials of Phase 2 . This indicates that only a small amount of generalization occurred between the vibrotactile stimulus and the tone-light compound.
The two groups which were switched from the light in Phase 1 to the tone-light compound in Phase 2 in the absence of the vibrotactile stimulus (A-500, A-1000) had a combined performance level of 90.3\% CRs on the last day of Phase 1 and $94.5 \%$ CRs on the first 10 trials of Phase 2 . The two groups which had these same treatments with the addition of the vibrotactile stimulus in Phase 2 had a combined performance level of $80.0 \% \mathrm{CRs}$ on the last day of Phase 1 and $76.8 \%$ CRs on the first 10 trials of Phase 2. The change in performance from Phase 1 to Phase 2 was reliably different for these two groups $[\mathrm{t}(40)=2.93, \mathrm{p}<.05]$. This outcome indicates that the introduction of the vibrotactile stimulus during the intertrial interval in Phase 2 produced a decrease in responding to the $\mathrm{AB}$ compound. This suggests that $\mathrm{X}$ was noticed by the subjects.

A parsimonious interpretation of this outcome is that generalization decrement is occurring. An alternative interpretation is that the posttrial stimulus is interfering with the associative process itself (e.g., Grevert \& Moore, 1970; Papsdorf \& Kettlewell, 1968). This is not particularly likely, however, because the negative associative impact of the posttrial distractor should be progressive rather than being fully present on the first 10 trials of Phase 2.

A detailed analysis was also made of the response pattern for the A-500 group at the beginning of Phase 2 when the CS-US interval was shifted from 500 to $1,000 \mathrm{msec}$. This change did not have a detrimental effect on the frequency of CRs. This group was responding at a $92.5 \%$ level on the last day of Phase 1 and responded at a $96.1 \%$ level on the first day of Phase 2. The A-500 group, however, did show a reliable change in the latency of its CRs during the first few days of Phase 2. Each CR for these animals was categorized by its onset latency; separate counts were made for CRs starting during the first $500 \mathrm{msec}$ of the 1,000 -msec CS-US interval and for those starting during the last $500 \mathrm{msec}$ of this interval. A summary of this analysis is presented in Table 2. The frequency of short-latency CRs decreased

Table 1

Summary of the Experimental Design and the Results

\begin{tabular}{|c|c|c|c|c|c|c|c|}
\hline \multirow[b]{2}{*}{ Group } & \multirow[b]{2}{*}{$\mathrm{n}$} & \multirow[b]{2}{*}{ Phase 1} & \multirow[b]{2}{*}{ Phase 2} & \multirow[b]{2}{*}{ Phase 3} & \multicolumn{3}{|c|}{ Percentage } \\
\hline & & & & & $\begin{array}{c}\text { CRs on } \\
\text { Last Day of } \\
\text { Phase } 1\end{array}$ & $\begin{array}{l}\text { CRs to } A B \text { on } \\
\text { Last Day of } \\
\text { Phase } 2\end{array}$ & $\begin{array}{l}\text { CRs to B on } \\
\text { First Day of } \\
\text { Phase } 3\end{array}$ \\
\hline HAB & 10 & & $\mathrm{AB}+$ & $\mathrm{B}+$ & & 96.7 & 75.7 \\
\hline HAB-X & 10 & & $\mathrm{AB}+, \mathrm{X}-$ & B+ & & 90.5 & 63.7 \\
\hline A-1000 & 10 & At & $\mathrm{AB}+$ & $\mathrm{B}+$ & 87.7 & 92.1 & 35.6 \\
\hline$A-1000-X$ & 9 & $\mathrm{~A}+$ & $\mathrm{AB}+, \mathrm{X}-$ & $\mathrm{B}+$ & 85.5 & 83.2 & 21.0 \\
\hline A -500 & 12 & $\mathrm{~A}+$ & $\mathrm{AB}+$ & B+ & 92.5 & 87.1 & 36.1 \\
\hline A-500-X & 10 & At & $\mathrm{AB}+, \mathrm{X}-$ & $\mathrm{B}+$ & 82.0 & 86.1 & 28.4 \\
\hline $\mathrm{X}-500$ & 9 & $X+$ & $\mathrm{AB}+$ & $\mathrm{B}+$ & 93.0 & 85.0 & 64.2 \\
\hline
\end{tabular}

Note $-A$ was a strobe light, $B$ was a tone, and $X$ was a vibrotactile stimulus. Reinforcement is designated by a " + " and nonreinforcement by a "-." 
Table 2

Frequency of CRs for Group A-500 Analyzed Separately for the First Half and the Second Half of the 1,000-Msec CS-US Interval During the First 2 Days of Phase 2

\begin{tabular}{lccc}
\hline & \multicolumn{3}{c}{ Percentage CRs } \\
\cline { 2 - 4 } & Trials & Trials & Trials \\
& $1-20$ & $21-40$ & $41-60$ \\
\hline First Half & & Day 1 & \\
Second Half & 10 & 78 & 52 \\
& & 33 & 50 \\
First Half & 56 & Day 2 & \\
Second Half & 38 & 24 & 14 \\
\hline
\end{tabular}

steadily across each of the first 2 days of Phase 3. At the same time, the frequency of long-latency CRs increased steadily. An analysis of this interaction using an appropriate linear contrast indicated a highly reliable trend for both Day $1[\mathrm{t}(11)=5.16$, $\mathrm{p}<.01]$ and Day $2[\mathrm{t}(11)=4.43, \mathrm{p}<.01]$. These outcomes indicate that the subjects changed their response pattern when the CS-US interval was altered. The extinction of the short-latency $C R$ and the simultaneous acquisition of a long-latency $C R$ suggests that new learning was occurring. In terms of Kamin's analysis, this implies that the US had become a "surprising" stimulus when the CS-US interval was shifted.

The subjects' performance on the first day of Phase 3 is also summarized in Table 1. A comparison of the subjects that experienced no training in Phase $1(69.7 \%$ CRs) with those receiving training to stimulus $A$ at the 1,000 -msec CS-US interval $(28.3 \% \mathrm{CRs})$ indicates that a strong blocking effect occurred $[\mathrm{t}(37)=5.57, \mathrm{p}<.001]$. This outcome indicates that the blocking effect observed by Marchant and Moore (1973) with their rabbit eyeblink preparation is not limited to a specific technique or to a specific set of conditioning parameters.

A comparison of the performance of the groups that were conditioned to $A$ in Phase 1 at a $500-\mathrm{msec}$ CS-US interval $(32.2 \% \mathrm{CRs})$ with those trained with $A$ at a 1,000 -msec CS-US interval $(28.3 \%$ CRs) indicated that the shift in the CS-US interval between Phase 1 and Phase 2 did not significantly attenuate the blocking effect [t(39) $=.34]$. This outcome is inconsistent with Kamin's explanation of the blocking effect.

A comparison of the response levels to $\mathrm{B}$ on the 1st day of Phase 3 for Groups A-1000-X and A-500-X (24.9\% CRs) with those for Groups A-1000 and A-500 (35.8\% CRs) indicated that the addition of the vibrotactile stimulus during the intertrial interval in Phase 2 did not attenuate the blocking effect. The observed difference was not significant $[\mathrm{t}(39)=1.47]$, and the direction of the sample means suggests a trend for more, rather than less, blocking to occur. This outcome does not support Neely and Wagner's (1974) supposition based on the Rescorla-Wagner model that events which enhance the contextual differences between Phase 1 and Phase 2 will lead to less blocking.

An alternate rationale for this outcome can be developed by postulating that the vibrotactile stimulus $(\mathrm{X})$ has cue properties which are shared by the tone (B). If this were the case, one might expect that the inhibitory role of $\mathrm{X}$ in Phase 2 might generalize to $B$ and thus reduce the response tendency to this stimulus and mask the blocking attentuation predicted by Neely and Wagner (1974). This interpretation seems to be contradicted by the low level of generalization observed between $\mathrm{X}$ and $\mathrm{AB}(12.2 \%$ CRs) on the first 10 trials of Phase 2 in Group X500 . Also, the fact that the X-500 group did not perform at a higher level in Phase 3 than the two habituation groups suggests that little associative transfer occurred between $\mathrm{X}$ and $\mathrm{B}$. If the excitatory strength which $X$ gained during Phase 1 had transferred to B, the performance of Group X-500 in Phase $3(64.2 \%)$ should have been superior to that of Group HAB (75.7\%).

These findings do not lend support to Kamin's (1969) interpretation of the blocking effect or to the formalization of his idea as represented by the Rescorla-Wagner model (Rescorla \& Wagner, 1972). Previous research with the eyeblink preparation has indicated that a shift in the CS-US interval produces a major change in the subject's performance (Boneau, 1958; Coleman \& Gormezano, 1971; Frey, 1970; Leonard \& Theios, 1967; Millenson, Kehoe, \& Gormezano, 1977; Prokasy \& Papsdorf, 1965). The data presented in Table 2 indicate that this manipulation was noticed by our subjects. For this reason, the shift manipulation should have produced a surprising US and therefore our failure to observe an attenuation of blocking in this group is not consistent with Kamin's hypothesis.

The vibrotactile stimulus introduced in Phase 2 midway through the intertrial interval produced a decrement in responding but did not attenuate blocking. This outcome is not consistent with Neely and Wagner's (1974) interpretation of the RescorlaWagner model. They have previously argued that any contextual change that makes the second phase more discriminable from the initial phase should produce generalization decrement. This should have the effect of reducing $\bar{V}$ in the Rescorla-Wagner equation and thereby should increase the $\lambda-\overline{\mathrm{V}}$ expression and permit additional learning (see Neely \& Wagner, 1974). Their interpretation leads to the prediction that the introduction of the vibrotactile stimulus in the present study should have attenuated blocking. Our results are not consistent with this prediction. 


\section{REFERENCES}

Boneau, C. A. The interstimulus interval and the latency of the conditioned eyelid response. Journal of Experimental Psychology, 1958, 56, 464-472.

Coleman, S. R., \& Gormezano, I. Classical conditioning of the rabbit's (Oryctologus cuniculus) nictitating membrane response under symmetrical CS-US interval shifts. Journal of Comparative and Physiological Psychology, 1971, 77, 447-455.

Dickinson, A., Hall, G., \& Mackintosh, N. U. Surprise and the attenuation of blocking. Journal of Experimental Psychology: Animal Behavior Processes, 1976, 2, 313-322.

FREY, P. W. Within-subject analysis of the CS-US interval in rabbit eyelid conditioning. Learning and Motivation, 1970, 1, 337-345.

Frey, P. W., \& Gavin, W. Overnight incubation of a partially conditioned eyeblink response in rabbits. Animal Learning \& Behavior, 1975, 3, 114-118.

Goodrich, K. P., Markowitz, J., \& Norman, D. A. An acamplification system for recording eyeblinks and other movements. American Journal of Psychology, 1964, 77, 127-128.

Gray, T., \& Appignanesi, A. A. Compound conditioning: Elimination of the blocking effect. Learning and Motivation, 1973, 4, 374-380.

Grevert, P., \& Moore, J. W. The effects of unpaired US presentations on conditioning of the rabbit's nictitating membrane response: Consolidation or contingency. Psychonomic Science, 1970, 20, 177-179.

KAm IN, L. J. Predictability, surprise, attention, and conditioning. In B. Campbell \& R. Church (Eds.), Punishment and aversive behavior. New York: Appleton-Century-Crofts, 1969.

Kettlewell, N. M., \& Papsdorf, J. D. The effects of an interpolated ITI stimulus on classical conditioning of the nictitating membrane response of the rabbit. Psychonomic Science, 1967, 9, 257-258.

Kohler, E. A., \& Ayres, J. J. B. The Kamin blocking effect with variable-duration CSs. Animal Learning \& Behavior, 1979, 7, 347-350.

Leonard, D. W., \& Theios, J. Effect of CS-US interval shift on classical conditioning of the nictitating membrane in the rabbit. Journal of Comparative and Physiological Psychology, 1967, 63, 355-358.

Marchant, H. G., \& Moone, J. W. Blocking of the rabbit's conditioned nictitating membrane response in Kamin's twostage paradigm. Journal of Experimental Psychology, 1973, 101, 155-158.

Millenson, J. R., Kehoe, E. J., \& Gormezano, I. Classical conditioning of the rabbit's nictitating membrane response under fixed and mixed CS-US intervals. Learning and Motivation, 1977, 8, 351-366.

NeELY, J., \& W AGNe R, A. R. Attenuation of blocking with shifts in reward: The involvement of schedule-generated contextual cues. Journal of Experimental Psychology, 1974, 102, 751-763.

PapsdorF, J. D., \& KetTlewell, N. M. The effects of different interpolated stimulus-conditioned stimulus intervals on the acquisition of the classically conditioned nictitating membrane response of the rabbit. Psychonomic Science, 1968, 10, 171-172.

Prokasy, W. F., \& Papsdorf, J. D. Effect of increasing the interstimulus interval during classical conditioning of the albino rabbit. Journal of Comparative and Physiological Psychology, $1965,60,249-252$.

RESCORLA, R. A. Variation in the effectiveness of reinforcement and nonreinforcement following prior inhibitory conditioning. Learning and Motivation, 1971, 2, 113-123.

Rescorla, R. A., \& Wagner, A. R. A theory of Pavlovian conditioning: Variations in the effectiveness of reinforcement and nonreinforcement. In A. H. Black \& W. F. Prokasy (Eds.)., Classical conditioning II: Current research and theory. New York: Appleton-Century-Crofts, 1972.

Suiter, R. D., \& Lolordo, V. M. Blocking of inhibitory Pavlovian conditioning in the conditioned emotional response procedure. Journal of Comparative and Physiological Psychology, 1971, 76, 137-144.

Tennant, W. A., \& Bitterman, M. E. Blocking and overshadowing in two species of fish. Journal of Experimental Psychology: Animal Behavior Processes, 1975, 1, 22-29.

Williams, B. A. The blocking of reinforcement control. Journal of the Experimental Analysis of Behavior, 1975, 24, 215-225.

(Received for publication December 1, 1978; revision accepted February 5, 1979.) 